\title{
Perspectivas das Políticas Públicas para Educação e Formação de Professores/as no Atual Contexto Político Brasileiro
}

\author{
Perspectives of Public Policies for Education and Teacher Training in the Current \\ Brazilian Political Context
}

\section{Perspectivas de las Políticas Públicas de Educación y Formación Docente en el Contexto Político Brasileño Actual}

\begin{abstract}
Angélica Cosenza ${ }^{1}$
Resumo

Este artigo tem o objetivo de problematizar a barbárie, enquanto impulso destrutivo, nas políticas públicas em educação e em formação de professores/as. Pra tanto, examina o conceito de barbárie gerencial e total, de Fernando Cassio, suas forças propulsoras e seus efeitos sobre a educação, contribuindo para fortalecer a educação democrática como direito de todos e todas, bem como a valorização e a dignidade profissional docente. Seu sentido na educação ambiental é o de alargar a conjuntura enquanto trajeto particular de uma rede de práticas que constituem as estruturas sociais, tornando possível melhor compreender como a educação ambiental forja-se nas relações com seus contextos macro de existência, explicitando possibilidades de transformação social, a partir da deslegitimação de certos discursos e fortalecimento de outros discursos contra-hegemônicos.
\end{abstract}

Palavras-chave: Políticas Públicas em Educação. Formação de Professores. Barbárie.

\begin{abstract}
This article aims to problematize barbarism, as a destructive impulse, in public policies in education and teacher training. To this end, it examines the concept of managerial and total barbarism from Fernando Cássio, its driving forces and its effects on education, contributing to strengthen democratic education as a right of all, as well as the valuation and professional dignity of teachers. Its meaning in environmental education is to broaden the conjuncture as a particular path of a network of practices that constitute social structures, making it possible to better understand how environmental education is forged in relations with its macro contexts of existence, explaining possibilities for social transformation, from the delegitimization of certain speeches and the strengthening of other counter-hegemonicspeechs.
\end{abstract}

Keywords: Public policies in Education. Teacher training. Barbarism.

\section{Resumen}

Este artículo tiene como objetivo problematizar la barbarie, como un impulso destructivo, en las políticas públicas en educación y formación docente. Con este fin, examina el concepto de barbarie gerencial y total, de Fernando Cássio, sus fuerzas impulsoras y sus efectos en la educación, contribuyendo a fortalecer la educación democrática como un derecho de todos, así como la valoración y la dignidad profesional de los docentes. Su significado en educación ambiental es ampliar la coyuntura como un camino particular de una red de prácticas que constituyen estructuras sociales, permitiendo comprender mejor cómo se forja la educación ambiental en las relaciones con sus macro contextos de existencia, explicando las posibilidades de transformación social. , desde la deslegitimación de ciertos discursos y el fortalecimiento de otros discursos contra-hegemónicos.

Palabras clave: Políticas públicas en educación. Formación docente. Barbarie.

\footnotetext{
${ }^{1}$ Profa. Dra. Faculdade de Educação e Programa de Pós Graduação em Educação/UFJF.
} 


\section{Introdução}

A pandemia Covid 19, causada pelo novo Coronavírus, SARS-CoV2, expõe milhões de seres humanos em todo o mundo ao desafio, como espécie, de repensar modos de vida. A forma com que vivemos em nosso planeta é um dos fatores que nos predispõe às pandemias. Mas o pano de fundo que nos impõe a pandemia do Covid 19 não é, necessariamente, novo, e sim,o mesmo que vem impulsionando a emergência climática: os padrões de consumo e a ideia de desenvolvimento infinito a que o capitalismo nos submete de forma mortífera.

A rápida disseminação do vírus demonstra um dos mais dramáticos limites do capitalismo global: a transnacionalização da produção, a circulação intensa de mercadorias, valores, pessoas e seres não humanos e a desproteção social nos âmbitos da saúde, educação, serviços e bens ambientais. Tais limites, internos à dinâmica do capital, para Foladori (2018, p. 165) dependem e se ajustam à distribuição em classes sociais: "La apropiación diferencial y clasista de los medios de producción conduce al también desigual metabolismo de las clases com la naturaleza externa", de forma que toda ação sobre a natureza é, também, uma transformação no interior da própria sociedade. O contágio situa a humanidade diante da barbárie dos lucros exorbitantes das corporações, da riqueza dos bilionários e da incapacidade dos Estados nacionais, capturados pela classe dominante, de preservar as vidas das massas populares.

Um aspecto dessa transnacionalização é o de que a modernidade produz vulnerabilidades que não pode controlar, e a desconfiança no triunfo das formas científicas, tecnológicas e institucionais tradicionais em responder a essas vulnerabilidades. Embora a vida moderna tenha reduzido ou eliminado muitos dos riscos de formas sociais anteriores, ela começou a fabricar os novos riscos que são percebidos como fora de controle, tal como o da pandemia. Nesse contexto, Beck (2011) já anunciava uma compreensão de imperceptibilidade, imprevisibilidade e incompensabilidade de novos riscos socioambientais.

A pandemia Covid 19 expõe a desigualdade no acesso aos cuidados de saúde, na possibilidade (ou não) de isolamento entre países e no interior de cada um deles. Ainda que alguns países do Sul possam demonstrar baixa contaminação, os efeitos econômicos da crise podem acirrar a pobreza em seu interior.

Davis (2020, p.9), ao trazer a realidade do sistema de saúde nos EUA, indica que aqueles com bons planos de saúde têm condições para isolamento domiciliar. Os funcionários públicos e outros grupos de trabalhadores/as sindicalizados/as com cobertura fazem escolhas difíceis entre renda e proteção. Entretanto, segundo o autor "milhões de trabalhadores com baixos salários, trabalhadores rurais, desempregados e sem teto estão sendo jogados aos lobos".

Harvey (2020) também lembra que a classe trabalhadora contemporânea, nos Estados Unidos (composta predominantemente por afro-americanos, latinos e mulheres assalariadas), enfrenta a desagradável escolha da contaminação ou do desemprego sem benefícios. É por isso que, para ele, a desigualdade não se dá somente pela classe, mas também por gênero e raça.

Partindo de uma lógica "moderna-colonizadora-capitalista-patriarcal-heteronormativa" (WALSH, 2017, p.2), a humanidade foi convertida em uma força de destruição. A crise socioambiental manifesta na degradação das florestas e oceanos, na emissão dos gases de efeito estufa que causam colapsos climáticos transnacionais, atinge amplas dimensões da vida natural e social, mas a questão climática é, sem dúvida, uma ameaça dramática, ainda que tenha efeito mais lento do que a pandemia aguda experienciada. Como o Painel Intergovernamental sobre Mudanças Climáticas - IPCC nos explica, se a temperatura média subir mais de $1,5^{\circ}$ acima do período pré-industrial, é provável que um processo irreversível de mudança climática seja posto em marcha. Assim, cientistas e, recentemente, os/as adolescentes vem repetindo e gritando que temos de mudar, urgentemente, a forma como 
vivemos, ou seremos condenados ao desaparecimento de parte da população ou à existência muito pior em um planeta hostil.

Para Lowy (2020, p11-12) a natureza sistêmica do problema é cruelmente ilustrada pelo comportamento dos governos, "todos eles (com raríssimas exceções) a serviço da acumulação de capital, das multinacionais, da oligarquia fóssil, da mercantilização geral e do livre comércio" enquanto outros, incluindo o presidente do Brasil Jair Bolsonaro, "são abertamente ecocidas e negacionistas do clima". A crise ambiental já é, e será ainda mais nos próximos meses e anos, a questão social e política mais importante do século XXI segundo Lowy (2020). Assim, sem a ampliação dos investimentos em saúde, educação e proteção ambiental, estaremos condenados a sucumbir em crises socioambientais que se acentuam cada vez mais, com efeitos severos à saúde de todo planeta.

Tomamos o caso da pandemia para problematizar a atual conjuntura porque ela agudiza a barbárie social contemporânea a que o capitalismo nos expõe. O Manifesto de Educadores Ambientais do OBSERVARE - Observatório da Educação Ambiental dá o tom das causas dessa crise. Criado em 2019, esse coletivo que reúne ambientalistas e educadores de todo Brasil, focados na possibilidade de produção de diálogos, manifestos, atos e táticas que possam fortalecer a educação ambiental no Brasil. Segundo o Manifesto:

[...] entendemos que a saúde pública e o bem-viver estão intrinsecamente ligadas a eficazes políticas educacionais e de cuidado ambiental. Compreendemos que o aparecimento de vários vírus, seus mutantes, as novas doenças, as epidemias e as pandemias têm origem na intensa destruição das florestas, das águas, do ar e da vida selvagem, entre outras ações de aniquilamento socioambiental. O meio ambiente é um sistema que exige cuidados, pois sua degradação fragiliza integralmente este complexo planeta (OBSERVARE, HOMEPAGE DA ENTIDADE, 2020).

O momento político no qual emerge a pandemia, é, sem dúvida, complexo e obriga aos gritos, que empregados, no sentido conferido por Walsh (2017, p. 17), podem conformar rachaduras e rupturas na ordem e nos padrões de poder, transição e revolução para nos distanciarmos do neoliberalismo que afeta, sobretudo os países do Sul. Para essa autora, uma nova racionalidade emerge dos modos de ser, dos processos de luta, dos povos afro, ameríndios, subalternizados.

Assim, desde o Sul, os gritos de que nos fala tomam parte de um espanto frente ao sistema capitalista/colonial que, para ela, está matando a todos. Frente à desesperança, a que e a como produzir pensamentos, ações, lutas. Os gritos, assim, ganham novos contornos e sentidos pedagógicos enquanto mecanismos, estratégias e ações de luta, rebeldia, resistência, desobediência, insurgência, ruptura e transgressão ante a condição imposta de silenciamento. No dizer de Walsh: "Son estas "pedagogizaciones" y agrietamientos que dan sustento y andanza a las esperanzas pequeñas, esperanzas que cuando empiezan a hablarse, aliarse y tejerse entre ellas, se hacen más fuertes y más imparables en su alentar, crecer y caminar" (WALSH, 2017, p. 38).

Nesse sentido, é que se faz urgente a produção de gritos em campos desguarnecidos de proteção social pelo grande capital. Um deles, constituidor da educação ambiental, é o campo da educação e, nele, a formação de professores/as. As ameaças à educação brasileira, incorporando aquelas, atualíssimas, advindas das estratégias de controle da pandemia exigem a publicização e o debate públicos; exigem, portanto que gritemos. A luta por escolas públicas democráticas, inclusivas, laicas, e com liberdade de ensinar, depende de tais gritos para defender projetos radicalmente democráticos, ante ao desmonte que, no dizer de Cássio (2019), ganha contornos de barbárie enquanto impulso destrutivo.

Este artigo tem, portanto, o objetivo de produzir esses gritos, problematizando a barbárie na educação e contribuindo para fortalecer a educação democrática como direito de 
todos e todas, bem como a valorização e a dignidade profissional docente. Seu sentido na educação ambiental é o de alargar a conjuntura enquanto trajeto particular de uma rede de práticas que constituem as estruturas sociais. Ao proceder à análise da conjuntura educacional, o/a pesquisador/a adquire melhor condição para compreensão de uma prática particular em educação ambiental, sobretudo em espaços escolares e outros ligados à formação de educadores/as ambientais.

Torna-se, assim, possível compreender como a educação ambiental forja-se nas relações com seus contextos macro de existência, explicitando possibilidades de transformação social, a partir da deslegitimação de certos discursos e fortalecimento de outros discursos contra-hegemônicos

\section{$2 \mathrm{O}$ direito à Educação em contraposição à Educação como oportunidade de negócios e como estratégia de dominação política}

Os limites interpostos à área educacional no cenário político e econômico, oriundos das políticas de ajuste fiscal adotadas pelo governo brasileiro, foram iniciadas em 2016, fortalecidas no governo Temer e retomadas no governo Bolsonaro, quando o conservadorismo neoliberal se agudizou. Dourado (2017) destaca que o processo de impeachment da presidente Dilma Rousseff e seus desdobramentos sinalizam para rebatimentos efetivos na democracia e no estado de direito no país, com adoção de políticas de ajuste fiscal na contramão de políticas sociais. Tais ajustes se traduzem em cortes em todas as áreas, incluindo a educação, pois reduzem verbas, impactam políticas e impedem novos investimentos. Os desafios do cenário político vigente, que acena para enfraquecimento das políticas sociais e para a melhoria no ambiente de negócios por meio da desregulação educacional pública, sinalizam, também, para um recuo na materialização das metas estabelecidas no Plano Nacional de Educação - PNE 2014-2024 (BRASIL, 2014) como política de Estado e como "epicentro das políticas educacionais" (DOURADO, 2017, p.23).

O PNE configurou-se, desde seus antecedentes históricos, como um ponto de concentração e de propagação das políticas educacionais, dispostas em metas e diretrizes, incluindo a destinação de $10 \%$ do Produto Interno Bruto para a educação, pela qual a

sociedade civil tanto reivindicou. É na luta pela efetividade da Lei e no combate ao desmoronamento de sua materialização que o PNE continua sendo o epicentro das disputas da política educacional. Cabe destacarmos, aqui, especialmente as metas 12, 15, 16, 17 e 18 e suas estratégias, que, articuladas às Diretrizes do PNE, estabelecem nexos para as políticas educacionais, consideradas, na educação superior, base para a formação inicial e continuada dos/as profissionais da educação, objetivando a melhoria desse nível de ensino e sua expansão.

Em Cássio (2019, p.17), também é possível uma compreensão desse cenário agudo que assola a educação nos últimos anos, a partir daquilo a que o autor denomina de barbárie gerencial e barbárie total. A barbárie gerencial expõe a educação como insumo econômico e figura nas agendas empresariais, para ele "cada vez mais capilarizadas e indistinguíveis das políticas educacionais oficiais". Segundo o autor, apresentando-se como novo, moderno, eficiente e responsável, o discurso empresarial, incorporado ao discurso governamental (manifesto em práticas sociais, sobretudo políticas públicas) e voltado à inovação das redes de ensino "produz esfacelamento dos sistemas públicos de ensino, rebaixamento da formação escolar dos mais pobres, desqualificação da atividade docente, redução do financiamento público, pauperização das escolas e ampliação dos processos de privatização". Tal discurso se apoia na ideia de que o problema da educação pública no Brasil não seria o da falta de recurso, mas, sim, o da gestão inadequada. 
Os resultados nas avaliações em larga escala são comumente utilizados como estratégias discursivas para convencimento de como anda mal o ensino e como isso fere o direito à aprendizagem de estudantes. Um aspecto de destaque é a tentativa de inculcar uma representação da escola pública como ineficaz. Inculcar, para o analista de discurso Norman Fairclough (2010), significa fazer com que as pessoas assumam discursos, posicionando-se dentro deles, agindo, pensando, falando e se vendo nos termos dos novos discursos. Os discursos são inculcados não somente como estilos (modos de usar a linguagem), mas também se materializam nos corpos, posturas, movimentos.

Para Fairclough (2010, p. 231), a ideia de um novo capitalismo se funda como uma ordem socioeconômica baseada no/dirigida pelo conhecimento e isso implica que também seja "dirigida pelo discurso". Dessa forma, para ele, a linguagem admite, hoje, papel mais significativo nas mudanças socioeconômicas contemporâneas do que no passado. Sendo assim, para esse autor, cabe aos cientistas sociais a compreensão sobre como são produzidos os efeitos ideológicos do discurso neoliberal sobre práticas sociais específicas.

Em paralelo à campanha difamatória e desqualificação do ethos da escola pública, que inclusive faz uso de muitos infográficos coloridos, entra em cena a produção simbólica do pensamento hegemônico da classe dominante, difundindo, agora, o perfil desejável da inovação: o da necessária parceria público-privada.

Partindo de tais forças é que se concretiza, discursivamente, também a ideologia da aprendizagem que, para Cássio (2019), não apenas reduz a complexidade dos problemas educacionais, como também denuncia o total desconhecimento de seus defensores em relação à escola pública real: os baixos salários dos educadores, a precária infraestrutura das unidades escolares e a situação econômica de estudantes e suas famílias. Dessa forma, esse autor anuncia que a barbárie gerencial tenta destruir as escolas de fora para dentro, enfraquecendo-a de recursos e deslegitimando-a quando interesses do empresariado são apresentados como interesses gerais.

O aprendizado é a apropriação individual da cultura ensinada, enquanto o ensino é papel dos/as educadores/as na mediação da aprendizagem. Desse modo, nas escolas se realiza o processo de ensino-aprendizagem, constituído por dois lados inseparáveis para produção de educabilidade e dependente de educadores/as e educandos/as. No entendimento de Cara (2019, p. 26), "a educação se concretiza em meio a processos educativos sistematizados ou não, tendo a escola o papel de criar condições para estudantes se apropriarem da cultura e até mesmo reinventá-la". A partir daí, o direito à educação configura-se como algo amplo, acolhedor dessa produção densa de apropriação de cultura como parte essencial da condição humana, necessária à vida e por isso mesmo "um direito humano".

Nessa defesa, para Lara (2010), como direito humano a educação assume a dimensão da totalidade da vida. Não é questão para determinado momento da existência, determinado conteúdo. A tarefa primeira desse espaço-tempo institucionalizado - quer seja a escola, o museu, a ONG, os parques e zoológicos - é educar para um educar-se contínuo. A escola, antes de ser dispositivo para assenhorear-se de saberes e atitudes já acumulados e tradicionalizados pelo grupo, é, sobretudo, o dispositivo que provoca e aguça a educabilidade do ser humano. Antes de se dizer capaz de contribuir para a educação, é importante que o espaço educativo e o/a educador/a se interroguem sobre a sua capacidade de ver, ouvir, sentir e interpretar o que a humanidade está sendo ou, melhor, como está acontecendo; como está a humanidade se questionando; quais anseios humanos se tornam crítica ao constituído, e apelo a um porvir melhor, como desafio e tarefa.

Também para Lara (2010), a escola é espaço-tempo institucionalizado, encarregado de produzir consciência crítica e atividade planejada para o cultivo da humanização. Segundo o autor, é preciso que, junto com os demais cultivos necessários para a sobrevivência da espécie humana, um cultivo exista que se debruce, com especial cuidado, sobre a produção das 
subjetividades. A escola precisa pensar criticamente a humanidade e, a partir desse pensar crítico, criar dispositivos que ajudem as novas gerações acederem ao nível de consciência e da sensibilidade, afinadas com a urgência da tarefa de descobrir-se como seres humanos integrados no conjunto dos outros seres, mas, também, em contraponto a eles, nas suas diferenças. É nessa direção que o direito à educação não se restringe à aprendizagem, ao aprender, não se restringe tão somente aos/às estudantes, mas ao processo contínuo de produção de sujeitos múltiplos e diversos. Nesse sentido é que a educação contribui para transformação de sujeitos e mundos, quando pautada no direito de todos/as à educação. Cara (2019) lembra que a própria Constituição Federal de 1988, em seu artigo 205, estabelece que a educação visa ao pleno desenvolvimento da pessoa, seu preparo para o exercício da cidadania e sua qualificação para o trabalho. Tal tríade reafirma o conceito de educação como apropriação da cultura, capaz de garantir uma leitura crítica do mundo.

O direito à educação torna possível a leitura crítica de mundo e, aqui, é preciso lembrar e reforçar Paulo Freire, patrono da educação brasileira, que nos diz:

\begin{abstract}
Não se trata, obviamente, de impor à população espoliada e sofrida que se rebele, que se mobilize, que se organize para defender-se, vale dizer, para mudar o mundo. Trata-se na verdade - não importa se trabalhamos com alfabetização, com saúde, com evangelização ou com todas elas -, de, simultaneamente com o trabalho específico de cada um desses campos, desafiar os grupos populares para que percebam, em termos críticos a violência e a profunda injustiça que caracterizam a sua situação concreta. Mais ainda, que sua situação concreta não é destino certo ou vontade de Deus, algo que não pode ser mudado (FREIRE, 2005, p.79).
\end{abstract}

É na perspectiva de os processos educativos contribuírem para a transformação social que o discurso emancipador encaminha as práticas e as lutas de uma educação contra a barbárie em movimentos articulados em fóruns, conselhos, associações de pesquisa e em tantos outros espaços de participação. No entanto, discursos outros, advindos de dois diferentes locais ilocucionários encaminham, desde 2016, a educação a funcionar como insumo econômico (para ultraliberais) e/ou estratégia de dominação política (para ultrarreacionários). Cara (2019) considera haver um pacto entre ultraliberais e ultrarreacionários para destruir o direito à educação estabelecido pela Constituição de 1988.

O ajuste fiscal defendido por esse pacto se traduz por cortes em todas as áreas, sobretudo as sociais de que a educação é exemplo, levando à estagnação, já que reduzindo verbas, impactam-se políticas e impedem-se novos investimentos, afetando as políticas educacionais, os salários, a empregabilidade e, assim, o crescimento.

Em 2017, o IBGE divulgou dados do PNAD - Programa Nacional de Pesquisas Contínuas por Amostra de Domicílios que retratavam a situação educacional do Brasil em 2016. O analfabetismo perdurava em $7,2 \%$ da população com mais de 15 anos de idade, perfazendo, naquele momento, 11,8 milhões de analfabetos. Entre os jovens de 14 a 29 anos, $33,4 \%$ estavam empregados, mas não matriculados em uma escola. $\mathrm{O}$ índice de $20,5 \%$ dos jovens retratavam aqueles/as que nem estudam e nem trabalham, ou seja, 24,8 milhões de jovens. $\mathrm{O}$ acesso ao ensino superior avançou no Brasil, mas ainda estava abaixo da média, pois somente $15 \%$ dos adultos (25-64 anos) chegam a essa etapa do ensino. O salário pago aos/as professores/as brasileiros também estava abaixo da média. Mas, apesar da gravidade dos dados, no governo Temer, tivemos a aprovação da Emenda Constitucional 95/2016 para congelamento de gastos públicos por vinte anos e a Reforma Trabalhista e, no Governo Bolsonaro, a aprovação, em 2019, da Reforma da Previdência Social com alterações significativas no regime de pensões e aposentadorias concedidas aos/às brasileiros/as.

O desmonte na Educação pública e gratuita ganha força. Se olharmos o orçamento da União para 2018-2019 podemos constatar a redução dos investimentos destinados à educação. 
Na educação básica, os cortes já vinham afetando recursos para o Fundo de Manutenção e Desenvolvimento da Educação Básica e de Valorização dos Profissionais da Educação (Fundeb), garantido pela PEC 15/2015, que ajuda a custear o salário de professores/as de escolas públicas em estados cuja remuneração não alcança o piso nacional da categoria, e pode ser usado também em atividades como o custeio de programas de melhoria da qualidade da Educação, da formação continuada dos/as professores/as, da aquisição de equipamentos e da construção e manutenção das escolas. Esse fundo, agora, segundo Freitas (2020a, AVALIAÇÃO EDUCACIONAL, BLOG DO FREITAS), envolve disputas entre agendas que advogam sua substituição por lógicas privadas de financiamento, seja pelo mercado ou terceiro setor, expressas pelos "vouchers e escolas charters". Está em curso uma emenda (EMC 3/2019) que altera o art. 3 da PEC 15/2015 e o art. 213 da Constituição Federal para possibilitar que estados e municípios optem por direcionar parte dos recursos do FUNDEB para organizações da sociedade civil e para financiar bolsas de estudo em instituições de ensino privadas. A emenda introduz um parágrafo no Artigo 213 da Constituição Federal, com a seguinte redação:

$\S 1^{\circ}$ Os recursos de que trata este artigo poderão ser destinados a bolsas de estudo para o ensino básico, na forma da lei, para os interessados inscritos e selecionados que demonstrarem insuficiência de recursos, quando houver instituições cadastradas segundo requisitos definidos em lei na localidade da residência do educando (MITRAUD; CALERO, 2019, p.01)

A Emenda é um estímulo ao mercado educacional, para que lucre com a oferta pública de ensino, pois a proposta permite que prefeitos e governadores transfiram a responsabilidade pela oferta educacional às escolas privadas por meio do pagamento de bolsas, em substituição aos governos nessa tarefa. Estarão os impostos, os fundos públicos, ou seja, o Estado, a financiar o empresariado. Na educação superior não é diferente, as forças empresariais, sob égide do Ministério da Educação, em 2019, agiram no sentido de apresentar para consulta pública o programa Future-se, que teria como objetivo o fortalecimento da autonomia administrativa, financeira e de gestão das Instituições Federais de Ensino Superior (IFES).

A abrangência do programa se refere a três eixos: 1) Gestão, governança e empreendedorismo; 2) Pesquisa e inovação; 3) Internacionalização. Aderindo ao programa, as IFES se comprometerão junto a, pelo menos, uma organização social a ser contratada. Os contratos de gestão seriam firmados pela União e pela IFES com a organização social, cujas atividades seriam dirigidas ao ensino, à pesquisa científica, ao desenvolvimento tecnológico, à cultura e estariam relacionadas às finalidades do Future-se. Em linhas gerais, as universidades estão rejeitando o Programa Ministerial, pois responsabiliza as instituições de ensino pelas capitalizações de recursos, livrando o Estado de tal responsabilidade.

Em tempos de pandemia, mais um fato social pode ser enquadrado na barbárie gerencial. Apesar da necessidade de fechar escolas para aumentar o distanciamento social e, com isso, diminuir a transmissão do coronavírus, a mimese da produtividade empresarial com a lógica da gestão com estabelecimento de metas e eficiência de resultados entra em cena para dizer que a educação não pode parar. A lógica é a de que a transmissão de conteúdos não pode parar e, para isso, as instituições precisam se valer de práticas não presenciais. Isso está impactando o sistema educativo, também as famílias, e acirrando debates sobre o ensino através de tais práticas, novas para muitas instituições.

A polêmica na educação básica gira em torno de transferir para o interior das famílias e casas a continuidade da educação dos filhos que estava em curso nas escolas, bastando, para isso, tecnologia. E, no ensino superior, a de ferir a autonomia didático-científica das universidades. Outra questão posta por muitas associações de pesquisa e sindicatos do campo da educação é que a forma aligeirada, sem planejamento, de uso contingencial de atividades à 
distância, pode trazer prejuízos à formação e desqualificar a $\mathrm{EaD}$ de qualidade social enquanto prática social formativa, dialógica e participativa.

Nessa direção, a Portaria 343 do Ministério da Educação, publicada em 18 de março de 2020, dispõe sobre a substituição das aulas presenciais por aulas em meios digitais enquanto durar a situação da pandemia. Na esteira dessa portaria, muitos governos estaduais e municipais têm determinado a mesma medida. A Associação Nacional de Pesquisa em Educação, em nota publicada em 29/03/2020, denuncia que a Portaria reforça o paradigma mercadológico de uso da EaD, voltada à economia de custo, valendo-se de larga utilização de broadcasting e da precarização das condições materiais de trabalho dos/as professores/as que dela participam. Dessa forma, boa parte do magistério está se desdobrando, tentando dar cobertura aos/às estudantes, mas isso implica em uma intensificação do trabalho em um momento em que ele, igualmente, também é atingido pela pandemia (ANPED, 2020).

$\mathrm{O}$ que, em princípio, parece ser uma resposta despretensiosa para o cumprimento do calendário letivo, frente ao isolamento social, pode, também, ser a porta de entrada para o aprofundamento da mercantilização da educação. As reformas educacionais em curso, os frequentes ataques à educação pública e aos/às profissionais da educação, a retirada de direitos da classe trabalhadora, via reformas trabalhista e da previdência, favorecem, principalmente, o grande capital, que vê o ensino público como ferramenta de rentismo. Junto a isso, a celeridade na publicação da Portaria 343 vale-se do momento de excepcionalidade e das condições impróprias para um debate com a sociedade (FREITAS, AVALIAÇÃO EDUCACIONAL, BLOG DO FREITAS, 2020b).

É nesse cenário que se instala a barbárie gerencial, cujos tentáculos avançam sobre importantes políticas públicas educacionais no Brasil (Quadro 1), fomentando os interesses empresariais que operam no campo educacional e a destinação de verbas públicas a estes.

\begin{tabular}{|c|c|}
\hline PROPOSIÇÃO/AÇÃO POLÍTICA & PRINCIPAIS PROBLEMATIZAÇÕES E CRÍTICAS \\
\hline $\begin{array}{l}\text { Enfraquecimento Plano Nacional de Educação } \\
\text { PNE (2014-2024) }\end{array}$ & $\begin{array}{l}\text { Descumprimento das Metas do PNE e do Custo Aluno } \\
\text { Qualidade Inicial (CAQi)e Custo Aluno Qualidade (CAQ), } \\
\text { base para investimento equivalentes a } 10 \% \text { do PIB em } \\
\text { políticas educacionais. Ver Dourado (2017). }\end{array}$ \\
\hline $\begin{array}{l}\text { Revisão do Fundo De Manutenção e } \\
\text { Desenvolvimento da Educação Básica e de } \\
\text { Valorização dos Profissionais da Educação } \\
\text { (Fundeb), garantido pela Pec } 15 / 2015\end{array}$ & $\begin{array}{l}\text { Comprometimento pela Emenda (EMC } 3 / 2019 \text { ) que altera o } \\
\text { art. } 3 \text { da PEC } 15 / 2015 \text { e o art. } 213 \text { da Constituição Federal } \\
\text { para possibilitar que estados e municípios optem por } \\
\text { direcionar parte dos recursos do FUNDEB para } \\
\text { organizações da sociedade civil e para financiar bolsas de } \\
\text { estudo em instituições de ensino privadas. Ver Freitas } \\
(2020 \text { a). }\end{array}$ \\
\hline $\begin{array}{l}\text { Proposição do Programa Future-Se para } \\
\text { inovação na Gestão das IFES }\end{array}$ & $\begin{array}{l}\text { Parcerias público privadas para inovação na gestão das } \\
\text { Instituições de Ensino Superior via Organizações Sociais. } \\
\text { Ver ANDIFES (2019). }\end{array}$ \\
\hline $\begin{array}{l}\text { Valorização do Pisa (OCDE) como meta de } \\
\text { desempenho e de testes padronizados para } \\
\text { atestar qualidade da Educação }\end{array}$ & $\begin{array}{l}\text { As atividades do Programme for International Student } \\
\text { Assessment(PISA) cria não só formas de avaliação em } \\
\text { escala mundial, mas também fundamentação específica } \\
\text { para discutir, falar e pensar sobre a educação. Os resultados } \\
\text { são comumente utilizados como estratégias discursivas para } \\
\text { convencimento de como anda mal o ensino e como isso fere } \\
\text { o direito à aprendizagem de estudantes. Professores/as são } \\
\text { apresentados como sendo responsáveis pela transformação, } \\
\text { desenvolvimento e qualidade da educação Ver Addey } \\
(2016) \text {, Pettersson e Molstad (2016). }\end{array}$ \\
\hline & $\begin{array}{l}\text { Centralização curricular em nível nacional. Críticas à frágil } \\
\text { participação popular e à concepção de fundo calcada no } \\
\text { direito à aprendizagem, que leva à organização curricular }\end{array}$ \\
\hline
\end{tabular}




\begin{tabular}{|c|c|}
\hline $\begin{array}{l}\text { Aprovação das bases nacionais comuns } \\
\text { curriculares para ensino fundamental e médio }\end{array}$ & $\begin{array}{l}\text { em termos de competências e habilidades alinhada ao } \\
\text { pensamento do empresariado brasileiro. Divergências } \\
\text { quanto à concepção de conhecimento, educação e currículo. } \\
\text { Invisibilização e exclusão de temáticas relacionadas aos } \\
\text { direitos humanos. Ver Silva e Filha (2019). }\end{array}$ \\
\hline Aprovação da reforma do ensino médio & $\begin{array}{l}\text { Críticas ao aligeiramento da formação de jovens de origem } \\
\text { trabalhadora e as possibilidades de aumento da } \\
\text { desigualdade social. Críticas ao conteúdo privatista e } \\
\text { conservador e à desvalorização do/a professor/a da } \\
\text { educação básica e retrocesso em torno de sua } \\
\text { profissionalização e formação. Críticas, sobretudo à } \\
\text { subordinação do Ensino Médio às demandas do mercado. } \\
\text { Ver Araújo e Silva (2019); Frigotto (2017). }\end{array}$ \\
\hline $\begin{array}{l}\text { Ampliação das vagas da UAB para } \\
\text { primeira/segunda licenciatura e ensino médio }\end{array}$ & $\begin{array}{l}\text { Crítica a expansão sem controle de qualidade da EAD pela } \\
\text { força do mercado educacional e incidência de empresários } \\
\text { do ramo frente aos tomadores de decisões em todas as } \\
\text { esferas estatais, inclusive regulatórias, e aportes de recursos } \\
\text { públicos.Ver Santos (2019). }\end{array}$ \\
\hline $\begin{array}{l}\text { Aprovação da base nacional comum para a } \\
\text { formação inicial de professores -BNC- da } \\
\text { formação (Resolução CNE/CP } \mathrm{n}^{\circ} \text { 2/2019) e } \\
\text { revogação da Resolução CNE/ CP n } \mathrm{n}^{\circ} \\
\text { 2/2015que instituiu as Diretrizes Curriculares } \\
\text { Nacionais para a Formação Inicial e } \\
\text { Continuada dos Profissionais do Magistério } \\
\text { da Educação Básica (DCNS) }\end{array}$ & $\begin{array}{l}\text { Crítica à ausência de participação social e à concepção de } \\
\text { formação de professores/as alinhada à BNCC. Crítica a } \\
\text { revogação da Resolução CNE/CP N } 2 / 2015 \text { em efetivação } \\
\text { em várias IES e, em seu lugar, a aprovação de uma } \\
\text { concepção de formação prescritiva e submetida às } \\
\text { competências e habilidades contidas na BNCC.Ver: Dossiê } \\
\text { Revista Formação em Movimento (2019). }\end{array}$ \\
\hline
\end{tabular}

Quadro 1 - A Barbárie Gerencial na Educação Brasileira, 2020.

Fonte: Produzido pela autora

Para Cássio (2019, p. 20) a outra face da barbárie é aquela que o autor denomina de barbárie total. Segundo ele, ela arromba a escola pelo lado de dentro e se manifesta por meio de: "intimidação, censura, anti-intelectualismo, revisionismo histórico, negacionismo científico, militarização, movimentos antiescola, moralismo, machismo, misoginia, transfobia, intolerância religiosa, racismo, violência como currículo e ódio como pedagogia". Junto dessa definição, acrescentamos outra qualificação que traduz também a barbárie total, com forte responsabilidade sobre a pandemia Covid 19: a antiecológica.

Layrargues (2017) aponta aspectos conjunturais da questão ambiental no cenário neoliberal contemporâneo, assumido pelo autor como antiecológico. Em suas palavras:

Existe uma determinação comum que demarca um amplo, diversificado, coeso e articulado conjunto de práticas que envolvem a degradação ambiental, os conflitos socioambientais, o desmonte da gestão ambiental governamental, a alteração de marcos regulatórios da legislação ambiental, a retórica desqualificadora dos ethos ecologistas, as ameaças jurídicas e de integridade física até o assassinato de lideranças ambientais. Este complexo conjunto de práticas comprometedoras da construção da sustentabilidade se encontra amplamente difundido, disseminado em todos os âmbitos da vida social hoje (LAYRARGUES, 2017, p.1).

Qualificando o ecologismo como um entrave ao desenvolvimento, o discurso antiecologista retoma a clássica oposição entre economia e ecologia, cuja justificativa repousa sobre a importância do extrativismo como condição necessária à retomada do crescimento econômico, associado à ideia da distribuição da riqueza gerada com a apropriação dos recursos naturais (LAYRARGUES, 2017).

$\mathrm{Na}$ introdução deste artigo, argumentamos como esse quadro, que ora qualificamos como antiecológico, parte de intenções negacionistas e ecocidas, dos interesses da acumulação de capital e pode produzir crises socioambientais, que se acentuam cada vez 
mais, provendo pandemias e outros severos riscos à saúde de todo planeta. Nesse aspecto, o quadro antiecológico da barbárie aponta para riscos à questão e à educação ambiental no Brasil. Primeiro, pelo severo desmonte da gestão ambiental pública e pela extinção da Política Nacional de Educação Ambiental (PNEA) nos organogramas do MEC e do MMA; segundo, pela interrupção do modelo democrático de gestão pública da PNEA e, terceiro, pela descontinuidade da trajetória conceitual da educação ambiental, compreendida, desde os anos 1990, como um ato político de formação cidadã para a participação social na defesa ambiental.

A barbárie total expõe os interesses dos atores ultrarreacionários, que se aprofundam no Brasil, no governo de Jair Bolsonaro, de seu ministro à frente do Ministério do Meio Ambiente e de sua ministra à frente do Ministério da Mulher, da Família, e dos Direitos Humanos. Para Cássio (2019), ultraliberais e ultrarreacionários divergem quanto à forma de operar a destruição da educação pública, mas trabalham articulados para dissolverem os pactos estabelecidos na Constituição de 1988. É possível, assim, dizer que esses dois ministérios, hoje, funcionam ao desserviço de destruição de dois desses pactos: o do direito à educação e o do direito ao ambiente.

Frigotto (2017, p. 21) nos lembra que foram os embates e as lutas no processo de elaboração e aprovação da Constituição de 1988 que, nos marcos da lei, ampliou os direitos sociais e subjetivos de forma significativa. Entre esses avanços, ele destaca "o direito universal à educação básica, incluindo os ensinos fundamental e médio; o reconhecimento de cidadania aos povos originários com a diversidade de sua cultura, suas línguas e suas crenças; a ampliação dos direitos dos portadores de necessidades especiais etc.”.

A Barbárie total encontra morada no movimento Escola Sem Partido (ESP), que abriu caminho para uma série de ataques às instituições educativas, sejam elas da escola básica ou do ensino superior, às políticas públicas inclusivas relacionadas aos direitos humanos (Quadro 2). Abriu disputas sobre o sentido de educar em projetos de lei contraditórios com a legislação educacional, disputas sobre critérios para geração de conhecimentos válidos, e, sobretudo, disputas sobre a que grupos sociais a educação, como direito, se encaminha.

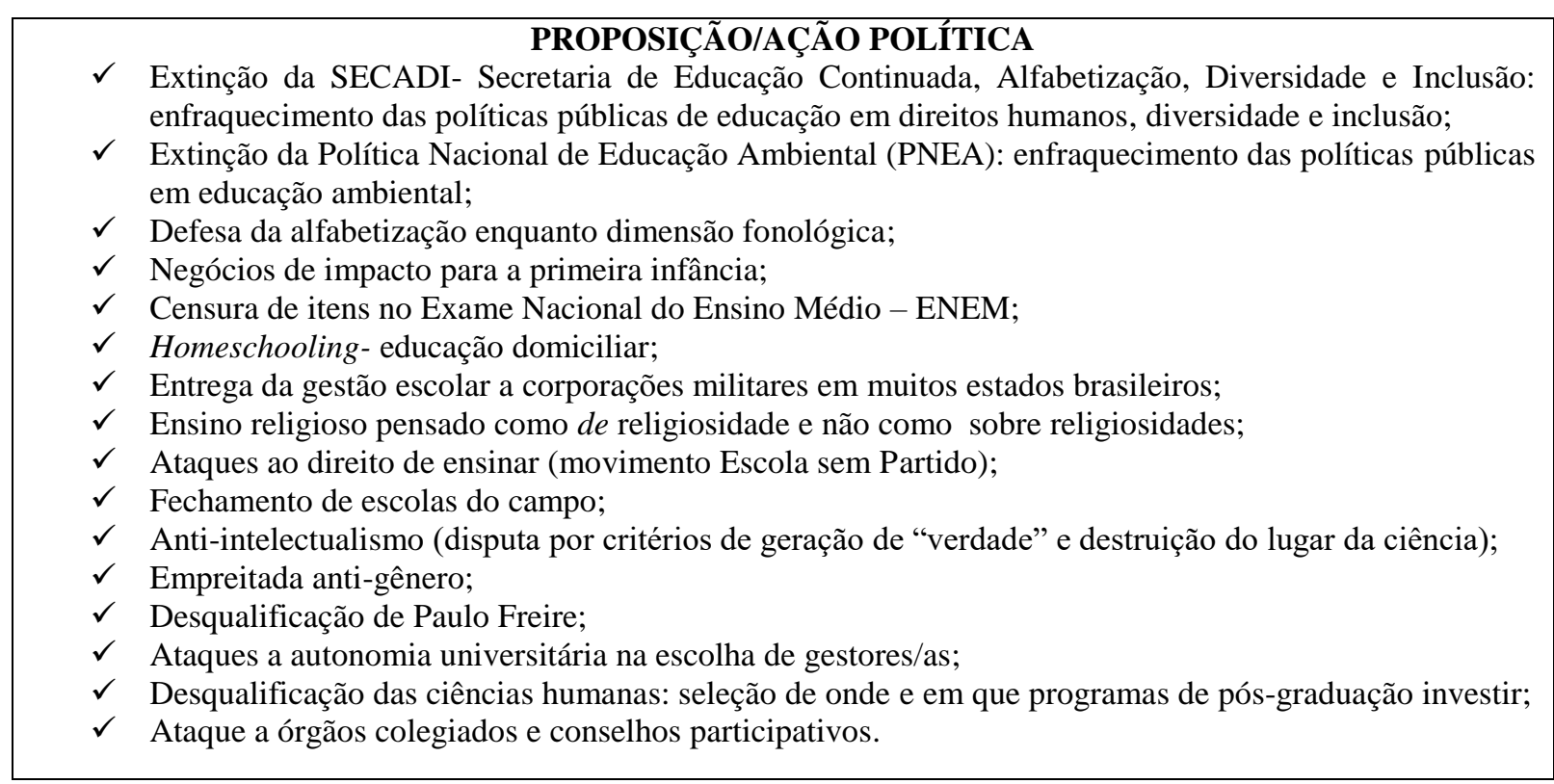

Quadro 2- A Barbárie Total na Educação Brasileira, 2020.

Fonte: produzido pela autora

Penna (2017, p. 114) busca pensar o Escola sem Partido como um discurso que vem sendo compartilhado desde 2004, quando o movimento foi criado, e que se apresenta desde 
então como uma "chave de leitura para entender o fenômeno educacional". O ESP, segundo esse autor, usa de quatro elementos principais: primeiro, uma concepção de escolarização que dissocia $o$ ato de educar do ato de instruir e aposta nesse último; segundo, uma desqualificação do/a professor/a; terceiro, estratégias discursivas fascistas; e, por último, a defesa do poder total dos pais sobre seus filhos. Mais recentemente, Penna (2018, p. 114 grifos do autor) descreve os lugares de sentido de onde frequentemente parte o discurso reacionário: "Professor- militante disfarçado, abusador, estuprador, sequestrador intelectual, não é educador; Aluno- audiência cativa, folha em branco, "meu filho, minhas regras"; Escolarização- relação de consumo, instrução, transmissão de conteúdo".

As teses do Escola sem Partido têm sua elaboração e desenvolvimento em setores ultrarreacionários das elites empresariais e de grupos político-religiosos que, por intermédio de intelectuais e parlamentares comprometidos com o atraso, já fazem sentir efeitos práticos na sociedade e na escola. Para Lino (2019) a recusa em reconhecer a complexidade do processo de ensino aprendizagem e a diversidade dos atores sociais que atuam e interagem nesse processo engendra soluções que, se na aparência se mostram milagrosas, em sua essência negam o próprio cerne da educação que é a diferença.

Frigotto (2017, p. 31) nos diz que, ao pôr entre aspas o termo sem da denominação Escola sem Partido, quer-se sublinhar que, ao contrário, trata-se da defesa ideológica hegemônica por seus arautos:

[...] da escola do partido absoluto e único: partido da intolerância com as diferentes ou antagônicas visões de mundo, de conhecimento, de educação, de justiça, de liberdade; partido, portanto, da xenofobia nas suas diferentes facetas: de gênero,de etnia, da pobreza e dos pobres etc.

A intolerância e a tentativa de dominação política se fazem evidentes em ações públicas como a extinção da SECADI, Secretaria de Ação continuada, Alfabetização, Diversidade e Inclusão, do Ministério da Educação, com inúmeros retrocessos à educação indígena, quilombola, do campo, em gênero e sexualidade, ambiental, etnicorracial. Militarização das escolas públicas e suas narrativas de qualidade, educação domiciliar,obscurantismo contra liberdade de ensinar e na censura a presença de determinados temas em provas nacionais, livros didáticos e políticas curriculares aludem ao que se espera da formação: submissão, invisibilização das demandas por igualdade e esvaziamento da capacidade de ação política via educação.

A barbárie - gerencial e total- avança, também, sobre as políticas de formação de professores/as, respectivamente por estratégias de conferir maior poder ao mercado na condução de seus negócios voltados ao oferecimento de cursos aligeirados de licenciatura à distância, cursos de formação pedagógica a bacharéis e de segunda licenciatura. Também, pela formatação do que conta como conhecimento válido à formação de professores/as e de sua articulação com a Base Nacional Comum Curricular para a educação básica. Esses aspectos são tratados na seção seguinte deste artigo.

\section{A formação de professores/as em meio à barbárie}

O debate em torno da formação dos/as profissionais da educação e da ampliação do acesso à educação pública não é novo, mas ocorre desde a promulgação da Constituição Federal de 1988. Desde então, concepções em disputa de educação, formação e profissionalização se fazem presentes no campo. Mais recentemente, sobretudo, com a instituição de conferências nacionais de participação da sociedade política e civil, a questão da formação de profissionais do magistério assumiu perspectiva mais ampla a partir da concepção de valorização desses profissionais,envolvendo a articulação entre formação inicial 
e continuada, carreiras, salários, condições de trabalho e saúde dos/as profissionais da educação. Merece destaque, nesse contexto, a implementação de políticas do Ministério da Educação direcionadas à formação dos/as profissionais da educação básica, tais como a constituição da Rede Nacional de Formação pelo MEC, a implementação do Parfor e do Pibid, a alteração na estrutura e funções da Capes, que passou a abrigar diretorias e conselho técnico científico vinculados à educação básica e a instituição da Universidade Aberta do Brasil, entre outros (DOURADO;TUTTMAN, 2019).

Já destacado na segunda seção deste artigo, a importância do processo de construção,tramitação complexa e participativa e a provação do Plano Nacional de Educação 2014/2024 (BRASIL, 2014) e, nele, as metas 15 a 18 que tratam da valorização dos/as profissionais da educação. Como um dos movimentos para alcançar metas do PNE no campo da formação de professores/as, ocorreu a aprovação, em 2015, das Diretrizes Curriculares Nacionais para a Formação Inicial e Continuada dos Profissionais do Magistério da Educação Básica (DCNs), por meio da Resolução CNE/CP n2/21015, de 1 de julho de 2015 (BRASIL, 2015).

A citada resolução pauta a concepção de formação tanto pelo desenvolvimento de sólida formação teórica e interdisciplinar para favorecer a educação de crianças, adolescentes, jovens e adultos e nas áreas específicas de conhecimento científico, quanto pela unidade entre teoria e prática e pela centralidade do trabalho como princípio educativo na formação profissional, como também pela valorização da pesquisa como princípio cognitivo e formativo. Importante ressaltar que tais concepções, historicamente, vêm sendo defendidas por entidades da área (DOURADO, 2015).

Frente à aprovação de tais diretrizes para a formação inicial em nível superior (cursos de licenciatura, cursos de formação pedagógica para graduados/as e cursos de segunda licenciatura) e para a formação continuada (BRASIL, 2015), tem-se, para os cursos de licenciatura, o aumento da carga horária de 2.800 horas para 3.200 horas a realizar-se em, no mínimo, quatro anos, e dentre outras deliberações, alarga o tempo dedicado às dimensões pedagógicas em, no mínimo, um quinto da carga horária total do currículo.

No âmbito das IES, as DCNs, oportunizaram a construção de Projetos Pedagógicos Institucionais de Formação de Professores (PPI) e, advindos desses, os Projetos Pedagógicos de Cursos (PPC), visando estabelecer condições institucionais para a construção da identidade e valorização de cursos de licenciaturas em formação inicial e continuada, além de avançar na superação do tradicional formato $3+1$ (três anos de disciplinas específicas e um ano de disciplinas pedagógicas), bandeiras históricas dos movimentos acadêmicos e sociais em formação docente. Estabelecem, também, que o projeto de formação deve ser elaborado e desenvolvido por meio da articulação entre a instituição de educação superior e o sistema de educação básica, envolvendo a consolidação de fóruns permanentes de apoio à formação docente. E assim, em regime de colaboração, permite à instituição formadora definir no seu projeto institucional as formas de desenvolvimento da formação inicial dos/as profissionais do magistério da educação básica articuladas às políticas de valorização desses/as profissionais.

As DCNs dão centralidade ao trabalho como princípio educativo na formação profissional e permitem a relação processual entre conteúdos e espaços formativos das ciências de origem e conteúdos do campo pedagógico, ao longo de todo percurso formativo inicial e continuado, evidenciando que os/as profissionais do magistério da educação básica compreendem aqueles que exercem atividades de docência e demais atividades pedagógicas, incluindo a gestão educacional dos sistemas de ensino e das unidades escolares de educação básica, nas diversas etapas e modalidades de educação.

No referido documento destacam-se alguns princípios: a) a docência como atividade profissional intencional e metódica, b) o currículo como construção e como processo histórico, c) a articulação com a Educação Básica e outros espaços educativos escolares e não 
escolares, d) o conhecimento como práxis social, e) a educação em e para os direitos humanos como um direito basilar, enquanto espaço coletivo de produção e disseminação de conhecimentos, de respeito às diversidades, de formação de valores democráticos e de convivência cultural e política. Nessa direção, as DCNs reconhecem tais princípios como estratégicos na formação das/os profissionais do magistério e na ação educativa, em consonância, também, com as Diretrizes Nacionais para a Educação em Direitos Humanos (BRASIL, 2010).

Em Dourado e Tuttman (2019) é possível apreender que a defesa da referida Resolução sinaliza concepções fundamentais para a melhoria da formação inicial e continuada e suas dinâmicas formativas, expressas em algumas considerações, dentre elas a de que:

A igualdade de condições para o acesso e a permanência na escola; aliberdade de aprender, ensinar, pesquisar e divulgar a cultura, o pensamento, a arte e o saber; o pluralismo de ideias e de concepções pedagógicas; o respeito à liberdade e o apreço à tolerância; a valorização do profissional da educação; a gestão democrática do ensino público; a garantia de um padrão de qualidade; a valorização da experiência extraescolar; a vinculação entre a educação escolar, o trabalho e as práticas sociais; o respeito e a valorização da diversidade etnicorracial, entre outros, constituem princípios vitais para a melhoria e democratização da gestão e do ensino (DOURADO; TUTTMAN, 2019, p. 200).

Depreende-se da Resolução que a formação inicial e continuada deve contemplar:
$\checkmark$ Sólida formação teórica e interdisciplinar dos profissionais;
$\checkmark$ A inserção dos estudantes de licenciatura nas instituições de educação básica da rede pública de ensino, espaço privilegiado da práxis docente;
$\checkmark$ O contexto educacional da região onde será desenvolvido;
$\checkmark$ Atividades de socialização e avaliação dos impactos;
$\checkmark$ Aspectos relacionados à ampliação e ao aperfeiçoamento do uso dalíngua portuguesa e à capacidade comunicativa, oral e escrita, como elementos fundamentais da formação dos professores e àaprendizagem de Libras;
$\checkmark$ Questões socioambientais, éticas, estéticas e relativas a diversidade etnicorracial, de gênero, sexual, religiosa, de faixa geracional e sociocultural como princípios de equidade (DOURADO; TUTTMAN, 2019, p. 202)

A realidade concreta dos sujeitos que dão vida ao currículo e às instituições de educação básica, as características das crianças, adolescentes, jovens e adultos que justificam e instituem a vida da/e na escola, tomam espaço nos princípios da Resolução e possibilitam aos cursos de formação "a reflexão sobre as relações entre a vida, o conhecimento, a cultura, o profissional do magistério, o estudante e a instituição" (DOURADO; TUTTMAN, 2019, p. 201)

As considerações e os princípios que a Resolução evocam não reduzem a formação docente a um simples como fazer. Ao contrário, posicionam o percurso formativo na construção de uma sociedade socialmente justa, democrática e inclusiva (COSENZA et al, 2019). Apesar disso, ou talvez justamente por seu conteúdo democrático e emancipador, a partir do ano 2017, vozes conservadoras, contrárias à resolução, ecoaram e tomaram espaço no âmbito do próprio Conselho Nacional de Educação, levando à tentativa de inviabilizar a materialização da Resolução. Inicialmente, alterando por três vezes o prazo para cumprimento desta pelas IES e cursos de formação de professores/as, e com um acréscimo: contados da publicação da Base Nacional Comum Curricular. Posteriormente, revogando a Resolução $\mathrm{CNE} / \mathrm{CP} \mathrm{N}^{\circ} 2 / 2015$ e propondo formação prescritiva e submetida às competências e habilidades contidas na BNCC, aprovando nova Resolução CNE/CP No 2, de 20 de dezembro de 2019 (BRASIL, 2019) que define as Diretrizes Curriculares Nacionais para a Formação 
Inicial de Professores para a Educação Básica e institui a Base Nacional Comum para a Formação Inicial de Professores da Educação Básica (BNC-Formação).

Segundo Dourado (2019) a despeito desse quadro complexo e de insegurança jurídica, muitas universidades e institutos federais desenvolveram e vem desenvolvendo estudos e discussões direcionadas à construção e materialização de projeto institucional próprio, em atenção às DCNs, desde o ano de 2015. Nesse sentido, o Dossiê Formação do Magistério da Educação Básica nas Universidades Brasileiras: institucionalização e materialização da Resolução CNE CP No 2/2015, publicado em 2019, pela Revista Formação em Movimento da Associação Nacional pela Formação de Profissionais da Educação - ANFOPE, dá visibilidade a processos e projetos institucionais efetivados ou em construção à luz do referido documento, permitindo a sua socialização e disseminação, contribuindo para a ampliação de outras experiências e para a materialização da Resolução CNE/CP $N^{\circ} 2 / 2015$, respeitando a construção coletiva e democrática que a caracteriza.

Nessa direção, muitas instituições, dentre elas a ANFOPE (2019) e a ANPED (2019) produziram notas de repúdio à aprovação pelo CNE da Resolução que institui a Base Nacional Comum para a Formação Inicial de Professores/as da Educação Básica (BNCFormação). Segundo nota da ANFOPE:

Em tempo recorde, o CNE desprezando o posicionamento das entidades e seus
argumentos, aprova em sessão pública, totalmente esvaziada, pois não divulgada, a
'nova' Resolução sem discussão com o campo educacional. Essa 'nova' Resolução
é mais um retrocesso educacional pois descaracteriza a formação docente
afrontando a concepção da Base Comum Nacional dos cursos de formação de
professores, que articula indissociavelmente a formação e a valorização dos
profissionais da educação, defendida historicamente pela ANFOPE. Essa
aprovação acelerada, sem discussão, visa desmontar um processo em curso nas
IES de todo o país, que nos últimos anos se dedicaram a reformular seus
cursos de licenciatura conforme determinava a Resolução 02/2015, dentro do
prazo previsto pelo CNE, que prorrogou sua implementação até dezembro de 2019 .
Consideramos tal atitude um desrespeito às instituições de ensino superior que
efetuaram um grande esforço para construir projetos institucionais de formação
de professores, assim como aos professores e estudantes dos cursos de
licenciatura, e às próprias decisões do CNE. Tal medida compromete aelevação
da qualidade dos cursos de formação e da educação brasileira, e anula os
avanços propostos pela Resolução $02 / 2015$ (ANFOPE, 2019)

A ANPED, em sua nota Uma formação Formatada (ANPED, 2019) chama a atenção para a perda do caráter público das políticas educacionais, com graves mudanças na formação de professores/as do país na perspectiva de moldar-se à lógica privatista e mercadológica da expansão de cursos de licenciatura privados e à distância. Centrar a formação de professores/asna BNCC constitui o reducionismo de1) formar a partir de competências que desconsideram a necessidade de enfrentar os desafios atuais da educação, 2) perder a dimensão da importância da formação da educação em direitos humanos, 3) correr o risco de perder a especificidade pedagógica e teórica de um documento de formação de professores/as em nível nacional,4) ter de rever diretrizes para formação de professores/as em função de revisão de diretrizes relativas à educação básica.Na nota da ANPED ressoa, também, a crítica à apresentação na atual Resolução sobre a formação/complementação pedagógica para graduados/as não licenciados/as e professores/as da Educação Profissional Técnica de Nível Médio como modo equivalente à licenciatura, permitindo a um/uma bacharel, tornar-se professor/a em seis meses.

A natureza da barbárie, aqui, se qualifica pelo desmonte de uma resolução emancipadora que posiciona o percurso formativo na construção de um/a professor/a criativo, propositivo, solidário e sensível às causas sociais que tanto adentram a escola, identificadas 
com a construção de uma sociedade socioambientalmente justa, democrática e inclusiva, a favor de outra predefinida em competências, alheia a formação teórico-prática, de construção aligeirada, que silencia temas vitais à formação como os socioambientais, de gênero e etnicorraciais.

\section{Considerações Finais}

Latour (2020), que vem há anos empreendendo estudos sobre a questão climática, em recente escrito sobre a pandemia, admite haver uma crise sanitária (algo mais passageiro), embutida em algo muito maior e duradouro: uma mutação ecológica duradoura e reversível concatenada pela gravidade das mudanças climáticas. Para ele, precisamos aproveitar a primeira para descobrir formas de adentrar a segunda. Uma das lições que o coronavírus nos dá, segundo ele, é a de que "em questão de semanas, pudemos suspender, em todo o mundo e ao mesmo tempo, um sistema econômico que até agora nos diziam ser impossível desacelerar ou redirecionar".

Por endossar o discurso de desacelerar, frear o ritmo com o qual vivemos, mudar a rota dos modos de produção e vida, o ecologismo foi sempre qualificado como um entrave ao desenvolvimento e o discurso antiecologista sempre retomou a clássica oposição entre economia e ecologia, cuja justificativa repousa sobre a importância do extrativismo como condição necessária à retomada do crescimento econômico, associado à ideia da distribuição da riqueza gerada com a apropriação dos recursos naturais (LAYRARGUES, 2017).

Em paralelo à campanha difamatória e desqualificação do ethos ecologista/ambientalista crítico, entra em cena, com mais força a partir da Rio92, a produção simbólica do pensamento hegemônico da classe dominante, difundindo o perfil desejável dos negócios verdes, da proteção ambiental via desenvolvimento sustentável. É importante apontar que o movimento em defesa do desenvolvimento sustentável, sobretudo o empresarial, tem suas raízes no compatibilismo. A concepção hegemônica de desenvolvimento sustentável deriva de um interesse em conciliar desenvolvimento com preservação ambiental, mas dentro da ótica do sistema de valores capitalistas vigente. Em suma, essa concepção emerge da ideia de se mudar a aparência, mas conservar a essência.

O interesse pelo desenvolvimento da qualidade ambiental no setor empresarial não se faz por nenhum projeto transformador no qual as relações sociais e econômicas estariam embasadas em uma nova racionalidade ecológica. Ao contrário, o núcleo central dos valores da sociedade capitalista tais como o individualismo, o mercado, a produtividade máxima e a competição, continua inalterado. A racionalidade por detrás do discurso empresarial continua sendo a econômica de mãos dadas com o mercado verde (LAYRARGUES, 2000).

Segundo Harvey (2012), os interesses dominantes da classe capitalista e dos desenvolvedores se atrelaram aos de setores mais progressistas, da mesma maneira como produzem todo o resto: como um empreendimento especulativo, muitas vezes com a conivência e a cumplicidade do aparelho do Estado. Nessa direção, podemos indagar se o mundo pós-corona, que está respondendo à crise sanitária, responderá, também, à mutação ecológica de que nos fala Latour (2020). As forças de mercado dentro desse sistema produtivo são capazes de realizar uma sustentabilidade social, plural, complexa, global e coerente?

O que o novo Coronavírus nos traz no atual quadro de degradação da vida - baseado em valores como o individualismo, a competitividade, a exclusão, a produção e o consumo exacerbados - poderá ser revisto a partir de uma nova ética, que busque romper com todo um sistema de valores que marca a política, a ciência, a educação e a cultura. Segundo Latour (2020) "agora é que é a hora de fazer o balanço de fim de ano. À exigência do bom senso: retomemos a produção o mais rápido possível, temos de responder com um grito: de jeito nenhum! A última coisa a fazer seria voltar a fazer tudo o que fizemos antes. O que queremos 
e o que não queremos ver renascer nesse mundo após retomada? É o convite que Latour nos faz.

E, desde já, recapitulemos os gritos e as gretas de que nos fala Walsh (2017) para imprimir novo marco contra toda forma de necropolítica que massacra os direitos sociais e nos empurram ao chão:

[...]aprender a pensar y actuar en sus afueras, fisuras y grietas, donde moran, brotan y crecen los modos-otros, las esperanzas pequeñas. Las grietas se han convertido en parte de mi localización y lugar. Son parte integral también de las transgresiones, indisciplinamientos, rupturas y desplazamientos que me obligan a mirarme críticamente, a aprender a desaprender para reaprender a pensar, actuar, sentir y caminar decolonialmente, a nivel individual y en colectividad (WALSH, 2017, p. 38).

Aqui e ali será preciso voltar a esses gritos, a essas produções de fissuras e gretas no amplo campo da educação, na formação de professores/as e na educação ambiental, como possibilidade para modos de vida transgressores a gerar sementes de vida "que dan sustento y andanza a lãs esperanzas pequeñas, esperanzas que cuando empiezan a hablarse, aliarse y tejerse entre ellas, se hacen más fuertes y más imparables em su alentar, crecer y caminar" (WALSH, 2017, p. 38).

As pedagogias da resistência afirmadas no direito à educação e no direito ao ambiente serão mais do que nunca necessárias nas lutas contra os interesses ultraliberais e ultrarreacionários. Rever os sentidos que tomam parte da conjuntura pré-crise, quais sejam: antiecologista, antiescola, anti-intelectualismo, negacionista,dentre outros, é fundamental à tessitura de compromisso ético-político-pedagógico nos campos educativo e ambiental, anunciando a radicalidade da luta anticapitalista como asas à sinalizar pertencimentos para além do capital, afinal como nos diz o poeta Manoel de Barros (BARROS, 2009, P. 11) : "no achamento do chão também foram descobertas as origens do vôo".

\section{Referências}

ADDEY, C. O PISA para o desenvolvimento e o sacrifício de dados com relevância política. Educ. Soc., Campinas, v.37, n.136, p. 685-706, 2016.

ASSOCIAÇÃO NACIONAL DOS DIRIGENTES DAS INSTITUIÇÕES FEDERAIS DE ENSINO SUPERIOR - ANDIFES. Homepage da representante oficial das universidades federais. Algumas manifestações de universidades sobre o Programa Future-se. 2019. Disponível $\mathrm{em}:<\mathrm{http}: / / \mathrm{www}$.andifes.org.br/veja-manifestacoes-universidades-federais-sobre-future-se/>. Acesso em: 23 mai. 2020.

ASSOCIAÇÃO NACIONAL PELA FORMAÇÃO PROFISSIONAIS DA EDUCAÇÃO- ANFOPE. Homepage oficial da entidade. Anfope repudia a aprovação pelo CNE da Resolução que define as novas Diretrizes Curriculares para Formação Inicial de Professores da Educação Básica e Institui a Base Nacional Comum para a Formação Inicial de Professores da Educação Básica (BNC - Formação), em sessão realizada no dia 07 de novembro, sem divulgação. 2019. Disponível em: $<$ https://www.anfope.org.br/anfope-repudia-a-aprovacao-pelo-cne-da-resolucao-quedefine-as-novas-diretrizes-curriculares-para-formacao-inicial-de-professores-da-educacao-basica-einstitui-a-base-nacional-comum-para-a-formacao-in/>.Acesso em: 23 mai. 2020.

ASSOCIAÇÃO NACIONAL DE PÓS-GRADUAÇÃO EM EDUCAÇÃO - ANPED. Homepage oficial da entidade. Manifestação Contrária à Portaria 343/2020 - MEC. 2020. Disponível em: <http://www.anped.org.br/news/manifestacao-contraria-portaria-3432020-mec >.Acesso em: 23 mai. 2020 . 
ASSOCIAÇÃO NACIONAL DE PÓS-GRADUAÇÃO EM EDUCAÇÃO- ANPED. Homepage oficial da entidade.Uma formação formatada. Posição da Anped sobre o texto referência - diretrizes curriculares nacionais e base nacional comum para a formação inicial e continuada de professores da educação básica. 2019. Disponível em: <http://www.anped.org.br/news/posicaoda-anped-sobre-texto-referencia-den-e-bncc-para-formacao-inicial-e-continuada-de>. Acesso em: 23 mai. 2020.

ARAÚJO, R. M, L; SILVA, G. P. A Reforma do Ensino Médio do Governo Temer e a Vulnerabilização do Professor da Educação Básica. SILVA, F. C. T.; FILHA, C. X. (Orgs.).Conhecimentos em Disputa na Base Nacional Comum Curricular. Campo Grande: Ed. Oeste, 2019. p. 143-154.

BARROS, M. O Guardador de Águas. Rio de Janeiro: Record, 2009.

BECK. U. Sociedade de Risco. Rumo a uma outra modernidade. São Paulo: Editora 34, 2011.

BRASIL, Programa Nacional de Direitos Humanos (PNDH-3) / Secretaria Especial dos Direitos Humanos da Presidência da República. Brasília: SEDH/PR, 2010.

BRASIL. Casa Civil. Lei $n^{\circ} 13005$, de 25 de junho de 2014. Aprova o Plano Nacional de Educação PNE e dá outras providências. Brasília: Casa Civil, 2014. Disponível em:

<http://www.planalto.gov.br/ccivil_03/_ato2011-2014/2014/lei/113005.htm>. Acesso em: 23 mai. 2020.

BRASIL. Ministério da Educação. Conselho Nacional de Educação. Resolução CNE/CP n. 02/2015, de $1^{\circ}$ de julho de 2015. Define as Diretrizes Curriculares Nacionais para a formação inicial em nível superior (cursos de licenciatura, cursos de formação pedagógica para graduados e cursos de segunda licenciatura) e para a formação continuada. Diário Oficial da União, Brasília, 2 de julho de 2015 - Seção 1 - p. 8-12. Disponível em:

<http://portal.mec.gov.br/docman/agosto-2017-pdf/70431-res-cne-cp-002-03072015-pdf/file>. Acesso em: 23 mai. 2020.

BRASIL. Ministério da Educação. Conselho Nacional de Educação. Resolução CNE/CP n. 02/2019, de 20 de dezembro de 2019. Define as Diretrizes Curriculares Nacionais para a Formação Inicial de Professores para a Educação Básica e institui a Base Nacional Comum para a Formação Inicial de Professores da Educação Básica (BNC-Formação). Diário Oficial da União, Brasília, 23 de dezembro de 2019 - Seção 1, p. 115-119.

CARA, D. Contra a barbárie, o direito à educação. CASSIO, F.(Org.). Educação contra a Barbárie: por escolas democráticas e pela liberdade de ensinar. São Paulo: Boitempo, 2019. p. 25-32.

CÁSSIO, F. Apresentação. Desbarbarizar a Educação. CASSIO, F. (Org.). Educação contra a Barbárie: por escolas democráticas e pela liberdade de ensinar. São Paulo: Boitempo, 2019. p. 15-24.

COSENZA, A. AMORIM, C. C.; Caminhos e Desafios na Construção de Projeto Pedagógico Institucional de Cursos de Licenciaturas: a experiência da UFJF. In: Dossiê Formação do Magistério da Educação Básica nas Universidades Brasileiras: institucionalização e materialização da Resolução CNE/CP n ${ }^{\circ}$ 02/2015, Rio de Janeiro, RJ, v. 1 n. 2. p. 239-257, 2019. Disponível em:<http://costalima.ufrrj.br/index.php/FORMOV/issue/view/108/DJ>. Acesso em maio/2020.

DAVIS, M. A crise do coronavírus é um monstro alimentado pelo capitalismo. et al.(Orgs.). Coronavírus e a luta de classes. Teresina/Fortaleza: Terra sem amos, 2020. p. 05-12. Disponível em: <https://terrasemamos.files.wordpress.com/2020/03/coronavc3adrus-e-a-luta-de-classes-tsa.pdf>. Acesso em: 23 mai. 2020.

DOSSIÊ temático: Formação do Magistério da Educação Básica nas Universidades Brasileiras: institucionalização e materialização da Resolução CNE/CP n 02/2015. Revista Formação em Movimento, Rio de Janeiro, v. 1, n. 2, inserir p. 01-620, 2019. Disponível em <HTTPS:// http://costalima.ufrrj.br/index.php/FORMOV/issue/view/108> Acesso em: 26 de maio de 2020. 
DOURADO, L. F.; TUTTMAN, M. Dossiê Formação do Magistério da Educação Básica nas Universidades Brasileiras: institucionalização e materialização da Resolução CNE/CP n 02/2015, Rio de Janeiro, v. 1 n. 2. p. 197-217, 2019. Disponível em http:// http://costalima.ufrrj.br/index.php/FORMOV/issue/view/108/DA. Acesso em maio/2020.

DOURADO, L. F. Diretrizes Curriculares Nacionais para Formação Inicial e Continuada dos Profissionais do Magistério da Educação Básica: concepções e desafios. Educação e Sociedade, Campinas, v. 36, n. 131, p. 299-324, Abr./Jun., 2015.

DOURADO, L. F. Plano Nacional de Educação: o epicentro das políticas de estado para a educação brasileira. Goiânia: Imprensa Universitária/ ANPAE, 2017.

FAIRCLOUGH, N. A dialética do discurso. Revista Teias, Rio de Janeiro, RJ, v. 11, n. 22, p. 225-234, Mai./Ago., 2010.

FOLADORI, G. Bases marxistas para la educación ambiental. Rev. Ambiente \& Educação, Rio Grande, RS, v. 23, n. 3, p. 159-169, 2018.

FREIRE, P. Pedagogia da Autonomia: saberes necessários à prática educativa. São Paulo: Paz e Terra, 2005.

FREITAS, L. C. Fundeb: mudança constitucional induz privatização. Homepage Avaliação Educacional, Blog do Freitas. 2020a. Disponível em:<https://avaliacaoeducacional.com/2020/03/18/fundeb-mudanca-constitucional-induzprivatizacao/>.Acesso em:23 mai. 2020.

FREITAS, L. C. Suspender as avaliações e unir os anos 20 e 21. Homepage Avaliação Educacional, Blog do Freitas. 2020b. Disponível em <https://avaliacaoeducacional.com/2020/04/02/suspender-asavaliacoes-e-unir-os-anos-20-e-21/> . Acesso em: 26 de mai.2020.

FRIGOTTO, G. A disputa da educação democrática em sociedade antidemocrática. In: Penna, F.; QUEIROZ, F.; FRIGOTTO, G.(Orgs.).Educação democrática: Antídoto ao Escola sem Partido. Rio de Janeiro: UERJ/LPP, 2018. p. 15-32.

FRIGOTTO, G. A gênese das teses do Escola Sem Partido: esfinge e ovo da serpente que ameaçam a sociedade e a educação. In: FRIGOTTO, G. (Org.) Escola "sem" Partido: esfinge que ameaça a educação e a sociedade brasileira/organizador Gaudêncio Frigotto. Rio de Janeiro: UERJ/LPP, 2017. p. 17-34.

HARVEY, D. O Enigma do Capital e as Crises do Capitalismo. São Paulo: Boitempo, 2012.

HARVEY, D. Política anticapitalista em tempos de COVID-19. In: DAVIS, M. et al.

(Orgs.).Coronavírus e a luta de classes. Teresina/Fortaleza: Terra sem Amos, 2020. p. 13-24.

Disponível em: <https://terrasemamos.files.wordpress.com/2020/03/coronavc3adrus-e-a-luta-declasses-tsa.pdf >. Acesso em: 23 mai. 2020.

LARA. T. A. Educação Corpo Inteiro. Ensino Em-Revista, Uberlândia, MG, v.17, n.1, p. 203-218, Jan./Jun.2010.

LATOUR. B. Imaginar gestos que barrem o retorno da produção pré-crise. Quais as atividades agora suspensas que você gostaria de que não fossem retomadas?Laboratório de Sensibilidades. Homepage da Inteligência Coletiva - Clube dos Saberes. 2020. Disponível

em:<https://laboratoriodesensibilidades.wordpress.com/2020/03/31/bruno-latour-imaginar-gestos-quebarrem-o-retorno-da-produc\%cc\%a $7 \mathrm{a} \% \mathrm{cc} \% 830$-pre-crise-quais-as-atividades-agora-suspensas-quevoce\%cc\%82-gostaria-de-que-na\%cc\%83o-fossem-retomadas/>.Acesso em: 23 mai. 2020.

LAYRARGUES, P. P. Antiecologismo no Brasil: reflexões ecopolíticas sobre o modelo do desenvolvimentismo-extrativista-predatório e a desregulação ambiental pública. In: OLIVEIRA, M.M.D., MENDES, M., HANSEL, C.M., DAMIANI, S. (Orgs.). Cidadania, Meio Ambiente e Sustentabilidade. Caxias do Sul: EDUCS, 2017. p.325-356. 
LAYRARGUES, P. P. Sistemas de Gerenciamento Ambiental, Tecnologia Limpa e Consumidor Verde: A Delicada Relação Empresa-Meio Ambiente no Ecocapitalismo. RAE - Revista de Administração de Empresas, São Paulo, v 40, n 2,. p. 80-88, Abr./jun. 2000.

LINO. L. Editorial. In: Formação em Movimento. Dossiê temático: Formação do Magistério da Educação Básica nas Universidades Brasileiras: institucionalização e materialização da Resolução CNE/CP n ${ }^{\circ}$ 02/2015, Rio de Janeiro,v. 1 n. 2. p. 193-195, 2019. Disponível em <http://costalima.ufrrj.br/index.php/FORMOV/issue/view/108/Ed2>. Acesso em mai. 2020.

LOWY, M. XIII Teses sobre a catástrofe iminente (ecológica) e as formas (revolucionárias) de evitála. In: Movimento: crítica, teoria e ação / Movimento Esquerda Socialista, Porto Alegre, Ano 5, v.1, n.16, p. 10-15, Jan./Mar. 2020.

MITRAUD, T.; CALERO, M. EMC 3/2019, PEC 01515: PEC 15/2015. 2019. Homepage da Câmara dos Deputados. Disponível em https://www.camara.leg.br/proposicoesWeb/fichadetramitacao?idProposicao=2206795. Acesso em: 26 mai. 2020.

OBSERVARE- OBSERVATÓRIO DA EDUCAÇÃO AMBIENTAL. Manifesto pela vida. 2020. Homepage da entidade. Disponível em:<https://observatorioea.blogspot.com/p/nos-educadores-eeducadoras-ambientais.html $>$. Acesso em: 23 mai. 2020.

PENNA, F. A. Escola sem Partido como chave de leitura do fenômeno educacional In: FRIGOTTO, G. (Org.) Escola "sem" Partido : esfinge que ameaça a educação e a sociedade brasileira Rio de Janeiro: UERJ,/LPP, 2017. p. 35-48.

PENNA, F. A. Construindo estratégias para uma luta pela educação democrática em tempos de retrocessos. In: Penna, F.; QUEIROZ, F.; FRIGOTTO, G. (Orgs.).Educação democrática: Antídoto ao Escola sem Partido. Rio de Janeiro: UERJ/LPP, 2018. p. 111-130.

PETTERSSON, D.; MOLSTAD, C.E.Professores do PISA: a esperança e a realização da educação. Educ. Soc., Campinas, v.37, n.136, p.629-645, 2016.

SANTOS, C. A. Educação a Distância: tensões entre expansão e qualidade. In: CASSIO, F.(Org.). Educação contra a Barbárie: por escolas democráticas e pela liberdade de ensinar. 1. Ed. São Paulo: Boitempo, p. 53-58, 2019.

SILVA, F. C. T.; FILHA, C. X. Conhecimentos em Disputa na Base Nacional Comum Curricular. Campo Grande: Ed. Oeste, 2019.

WALSH, C. Gritos, grietas y siembras de vida: Entretejeres de lo pedagógico y lodecolonial. In: WALSH, C. (Org.). Pedagogías decoloniales: Prácticas insurgentes de resistir, (re)existir y (re)vivir. TOMO II. Quit-Equadro: Ediciones Abya-Yala, 2017. p. 17-48. 